\title{
The surgical treatment of colorectal cancer in patients over seventy-five years old. Risk factor analysis in patients operated in election and in emergency
}

\author{
Alban Cacurri*, Roberto Cirocchi, Joanna Galanou, Ivan Barillaro, \\ Bledar Koltraka, Francesco Barillaro, Stefano Trastulli, Micol Sole Di Patrizi, \\ Giammario Giustozzi and Francesco Sciannameo
}

Address: Department of General and Emergency Surgery, S. Maria Hospital, Terni - University of Perugia, Italy

* Corresponding author

from XXI Annual Meeting of The Italian Society of Geriatric Surgery

Terni, Italy. 4-6 December 2008

Published: I April 2009

BMC Geriatrics 2009, 9(Suppl I):A26 doi:10.1 186/147I-23I8-9-SI-A26

This abstract is available from: http://www.biomedcentral.com/I47I-23I8/9/SI/A26

(C) 2009 Cacurri et al; licensee BioMed Central Ltd.

\section{Background}

The colorectal cancer has a high incidence and mortality in the geriatric population. However the advanced age does not represent a contraindication for the surgery, and a radical cancer surgical treatment guarantees the same life expectation of younger patients. In this study we analyzed the correlation between comorbidities, postoperative complications and mortality.

\section{Material and methods}

In our retrospective study we analyzed the clinical notes of 66 patients over 75 years.

We assessed the risk factors of the surgical treatment in the elective and emergency management. Among the 47 patients electively treated, 33 were affected by cardiocirculatory diseases, 23 by kidney diseases, 14 by metabolic and endocrine diseases, and 11 patients by respiratory diseases. In the 19 patients, who underwent emergency surgery, $75 \%$ had intestinal obstruction, and $25 \%$ had intestinal perforation.

In election were performed 14 anterior resection of rectum, 7 abdomino-perineal resections, 4 Hartmann procedures, 11 left hemicolectomies, 8 right hemicolectemies and 3 explorative laparotomies. In emergency were performed 5 ileostomies, 3 colostomies, 5 left hemicolecto- mies, 3 right hemicolectomies, 2 Hartmann procedures, and 1 explorative laparotomy.

\section{Results}

In elective surgery the complications were represented by suppuration of surgical wound (21.2\% of cases), cystitis (21.2\% of cases), bronchopneumonia (6.3\% of cases), dehiscence of the anastomosis (2.1\% of cases), thrombophlebitis of the lower limbs (2.1\% of cases). In emergency the complications were represented by suppuration of the surgical wound in $60 \%$ of cases, arrhythmias in $21 \%$ of cases, and acute renal failure in $5 \%$. In both elective and emergency surgery for patients without comorbidities there were not deaths. The mortality in patients with comorbidities was $2.1 \%$ in elective surgery and $26.5 \%$ in emergency surgery.

In election the comorbidities strictly related to the postoperative complications and mortality were the renal diseases, while the cardiocirculatory diseases influenced on post-operative complications only.

Contrary, in emergency the cardiocirculatory diseases influenced significantly the post-operative complications and mortality, while the renal diseases influenced only the post-operative complications. 


\section{Conclusion}

The colorectal cancer in advanced age does not present different characteristics from younger age. Because of the more accurate pre-operative and post-operative therapies it is possible to give geriatric patient the same radical surgery as younger patients. Particularly in elective surgery, thanks to an adequate preoperative preparation, the comorbidities can be corrected ensuring the same prognostic result of younger patients. Contrary in emergency, a considerable disagreement persists in terms of prognosis between geriatric patients and younger patients. This is related to the impossibility of performing an adequate pre-operatory preparation.
Publish with Biomed Central and every scientist can read your work free of charge

"BioMed Central will be the most significant development for disseminating the results of biomedical research in our lifetime. " Sir Paul Nurse, Cancer Research UK

Your research papers will be:

- available free of charge to the entire biomedical community

- peer reviewed and published immediately upon acceptance

- cited in PubMed and archived on PubMed Central

- yours - you keep the copyright

Submit your manuscript here:

http://www.biomedcentral.com/info/publishing_adv.asp 